\title{
A Fire Spread Model Based on Cellular Automaton
}

\author{
Hongpo Wang, Hong Zhou \\ School of Computer Science and Information Engineering, Tianjin Agricultural University, Tianjin, 300384, China
}

E-mail: zhouhong@tjau.edu.cn

\begin{abstract}
The Drum-Tower District is a historic site in the Inner place of Tianjin which represents the commercial culture, ecdemic culture, exotic culture and civilian culture of Tianjin. The buildings of this region are usually made of wood and other highly combustible materials. Once there be a fire, the influence will be very serious. The study of fire spread model Drum-Tower District is necessary. In the model of fire spread the cellular automaton rules were used. The effects of the different influence coefficients on the evacuation time were investigated, and the typical characteristics of space-time dynamics were analyzed. The numerical simulations show that the model is very good and can be used as a tool to predict fire.
\end{abstract}

Keywords-fire spread; cellular automaton; geographic information system (GIS)

\section{INTRODUCTION}

Many researches have been procedure by the scholars for the development of building fires, but the point which th ey investigated mainly with in only one building or very small places. Also the model which they used only describe the process fires spreading in one single material and and results of one building ${ }^{[1]}$. Few researchs concerned with two or more building. Ther efore the cellular automa ton(CA) model was used here for thereasonof it not only can repres ent the whole process, but can also describe the details of the fire spreading. This paper presents a fire spread model for Drum-Tower District of Tianjin based on cellular automaton.

\section{PROBLEM FormULATION AND PRELIMINARIES}

In the model of CA, the analysis area is generally di vides into equal - sized cells ${ }^{[2]}$. Each cell is a basic unit in the fire spread model, and the size of cell is determined by the places studied. Each cell has only one state according to the local circumstances. Each cell has the characteristics of the area it belongs to. The situation can change with time. Cells states can be impacted with each other specially for the neighboring cells according to update rules which are deter min ed from exp erience app lied to all the cells in this system $^{[3]}$. So a bidimensional CA model can be described for the target area. A two-dimensional grid can be created by dividing the research place. The state of each cell can be occupied by something like an obstacle or a pedestrian, also the state of each cell can be empty. One proxy can only occupy one cell at any time. If a proxy occupies a cell, then this proxy occupies the whole place of this cell. If there are two or more materials exist in one cell, the average prope rties are used which generated by the area method or the po wer method specially to handle with average proxy ${ }^{[4]}$. Of course there will be different situations, we will treate differently The area method me ans that the cell cha ra cteristics were determined by the largest material area in one cell. The cell characteristics are the most important mat erials in this cell in the power method. In the CA model, each house is regarded as an agent. We assume the fire can have nine possible action directions.

\section{MODEL DESCRIPTION}

\section{A. Cell size}

The narrow streets and densely-builting houses is the character of old places . In Drum-Tower District, builting are the same which means the house here are generally $2 \mathrm{~m}$ to 4 $\mathrm{m}$ wide and $4 \mathrm{~m}$ to $7 \mathrm{~m}$ long. The streets are generally $2 \mathrm{~m}$ to $4 \mathrm{~m}$ wide. So In this study, $3 \mathrm{~m}$ by $3 \mathrm{~m}$ cells was adopted for the numerical acc uracy and computation al efficiency bal anced within. the model uses two methods in different conditions, when two or more materials exist in cell. in $\mathrm{m}$ ost parts of the places, the area method can be used ; but for the power method, it can be only used to the important places, such as the ancient protected bui ldings ar ea and other important places. AS we know, in Drum-Tower District, there are many protected building.

\section{B. Cell characteristics}

In the study of Murosaki et al, the fire spread model was advanced .It showed that the fire spread most strongly affect by the weather conditions and the building materials ${ }^{[5]}$.

(1) Factors of buildings

The buildings in Drum-Tower District are mainly built of wood and soil and are generally 1 to 3 floors. But as the city develops, more and more modern build ings are now being built with many new buildings being built with a wi de var iety of stuffs. The mo del must inc lude all these situations and should be adaptable to further con ditions. people, in Drum-Tower District, enjoy their lives for the reason of sun-shine and the Haihe river.So the houses here have larger windows which have $4 \mathrm{~m}$ to $6 \mathrm{~m}$ in size than other regions and placess. Thus, they receive more sunshine; these large windows at the same time allow the fire's spread. It makes the fire spread more speedily and quickly. The buildings in Drum-Tower District were classified as: (1) 
brick buildings which have 1,2, or 3 floors, (2) steel and brick buildings which have $1,2,3$ to 6 floors, (3) steel buildings which have 2 to 9 floors, (4) earthen buildings which have 1 or 2 floors, (5) wooden buildings have 1 to 5 floors, and (6) other buildings. The different buildings have diff erent building par ame ters $\mathrm{S}$ and ratios of wo od $\mathrm{P}$. Except for the structural factors, the different build ings have diffe rent ways to get fire. The equation giv en by Wakamatsu was used to calculate $\mathrm{P}\left(\mathrm{t}_{\mathrm{k} 1}\right)$.

$$
\begin{aligned}
p t(i, j) & =\left\{\begin{array}{c}
\frac{4.0}{t_{2}-t_{1}} t(i, j)+\frac{0.2 t_{2}-4.2 t_{1}}{t_{2}-t_{1}}, t_{1} \leq t(i, j) \leq \frac{t_{2}-t_{1}}{5}+t_{1} \\
\frac{5}{4\left(t_{2}-t_{1}\right)}\left(-t(i, j)-t_{2}\right), \frac{t_{2}-t_{1}}{5}+t_{1} \leq t(i, j) \leq t_{2}
\end{array}\right. \\
t_{1} & =\left(3+\frac{3 a}{8}+\frac{8 d}{D}\right) /(1+0.1 v) \\
t_{2} & =\left(w_{f} / 5.5\right) /\left(A_{w} \sqrt{H} / A_{f}\right)
\end{aligned}
$$

where $p t(i, j)$ is the capability for the cell $[i, j]$ to catch the fire to spread. The time $t_{l}$ is looked as the cell $[k l]$ starts burning to when it began to spread of fire after catch fire. $a$ is the length of one cell, which usually is $4 \mathrm{~m}$. $d$, which is an unfixed vari able, will changes according to the time and conditions $^{[5,6]}$. For a given certain wind speed , $D$ is the fire can spread farthest distance, and calculated by ${ }^{[6]}$

$$
D=1.15(5+0.5 V)
$$

where $V$ is the wind velocity.

For the cell $[\mathrm{i}, j]$, the time from the cell get fire to the cell burned out is defined as $t_{2}$. The fire lo ad can be presented by $w_{f}$. According to the investigation made by the authors, $w_{f}$ for wooden structures or buildings is 60.0 , the fire load of earthen structures or buildings is 45.0 , the fire load of brick structures or building is 20.0, and for others structures or building that do not catch fire is 0.0 . For doors and windows, $A_{w}$ is the average open places in each floor. For each floor in one building, $A_{f}$ is the area and $H$ is height of it.

(2) Weather conditions

In the study of Jirou and Kobayashi, the farthest fire spreading distance equation was presented in $1997^{[7]}$. The equation is a function of only the wind direction and velocity. Fig. 1 shows the effect of the wind.

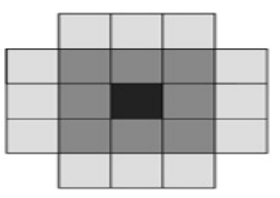

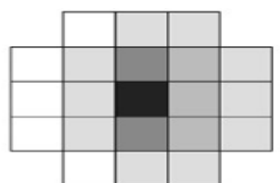

Fig. 1 Effect of wind

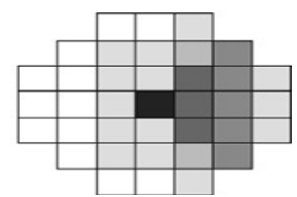

the cell will changes from situation(2) to situation (4),sometime after got fire. And also the situation of the cell will never change if the cell is in the situation of (1) or (5).

\section{D. danger degree}

When the target cell is chose, we may consider the value of the field of the aim cell and the local density distribution. Here, the total danger degree is defined as follows: have a fixed order. When the fire was catched in a cell, the state of the cell's state will transitie to state (2). The state of

$$
D(i+\Delta i, j+\Delta j)=(1-\beta) \times \frac{G(i+\Delta i, j+\Delta j)}{\sum_{\Delta i^{\prime}} \sum_{\Delta j^{\prime}} G\left(i+\Delta i^{\prime}, j+\Delta j^{\prime}\right)}+\beta \times \frac{N(i+\Delta i, j+\Delta j)}{\sum_{\Delta i^{\prime}} \sum_{\Delta j^{\prime}} N\left(i+\Delta i^{\prime}, j+\Delta j^{\prime}\right)}
$$

where $N(i+\Delta i, j+\Delta j)$ denotes the number of the houses in the aisles, where the fire of the lattice $(i, j)$ passes the cell $(i+\Delta i, j+\triangle j)$ and arrives the left (right), here, $\Delta i= \pm 3$, $\Delta j= \pm 3$ ). If the neighbouring lattice not occupied by a house or others, the values of $G$ and $N$ are 0 , the influence coefficient reflecting the strength of catching fire after the local density distribution is considered, and $0 \leq \beta \leq 1.0$.

\section{SIMULATION AND VisUALIZATION}

\section{A. Simulation}

The model of fire spreading must know whether the changes of cell[i,j] have between state (2) and (3). The fire spreading judgment index $F_{i j}$ determinthe cell's change pro bability. Cells with different characteristics have different $F_{i j}$. The indexes for cell-materials are based on the weather and cell characteristics.

Building rule: $F(i, j)=S_{i j} \cdot P_{i j} \cdot W_{i j} \cdot P t(i, j) \cdot \alpha \cdot w^{\gamma}$ (5)

Here, $S_{i j}$ is a building parameter, for wooden places, it be set to 1.0 , for steel buildings or places, it be set to 0.0 , and for other material, it be set from 0.0 to 1.0 . In the materials, the ratio of wood is presented by $P_{i j}$. And, accor ding to the distance from the burning grid, the wind effect in each cell is presented by w which varies from 0.0 to 0.6 . $\alpha(0<\alpha 1)$ is a parameter which it's value can adjust. That's means that it's value is changed to wind effects when the 
spreading velocity is small. $\gamma$, which determined the range and direction of the fire spreading, also is an suitable para meter to wind. In each cell, $W_{i j}$ is the loading for ability of easy to burn. When $F(i, j)$ is larger than a random value (between 0 and 1),the change between state (2) and state (3) of the situation for the cell will be happen, and having got fire for the cell is defined. When got fire time is more than $t_{1}$, the cell state will be changed to situation (4). When the the cell situation's got fire time is more than $t_{2}$, it will be changed to situation (5).

\section{B. Simulations result}

Based on the GIS model, we developed the DrumTower District fire spreading DLL(Dynamic Link Library). The parameters were $\alpha=0.2, D=12.0, \beta=1.1$, and $d=2.5$. For wooden structure $w_{f}=55.0, P=1.0$, for half combustible stuffs $w_{f}=40.0, P=0.7$, for almost not combustible stuffs $w_{f}$
$=15.0, P=0.3$, and for not combustible stuffs $w_{f}=0.0, P=0.0$. Figure 3 shows the Drum-Tower District fire spreading process . The wind was assumed to be from east direction, and the level of it is 3-4. burning cells be represented by the light gray and the burned out cells be represented by black gray.

Figure $2 \mathrm{a}$ shows that the fire has broken out. In Fig. $2 \mathrm{~b}$ the fire has spread over $1260 \mathrm{~m}^{2}$. Here, the wind direction is mainly affected the fire spread direction. In Fig. $2 \mathrm{c}$ at $\mathrm{t}$ $=150 \mathrm{~min}$, the fire has burned from cell-buildings to other thinks with $1218 \mathrm{~m}^{2}$ burned out. Once the other things like tr ees got fire, the fire spreads become quickly, as shown in Fig. $2 \mathrm{~d}$ at $\mathrm{t}=210 \mathrm{~min}$. Therefore, the fire scope and velocity depends on the cell chara cterist ics and some extra cond itions.

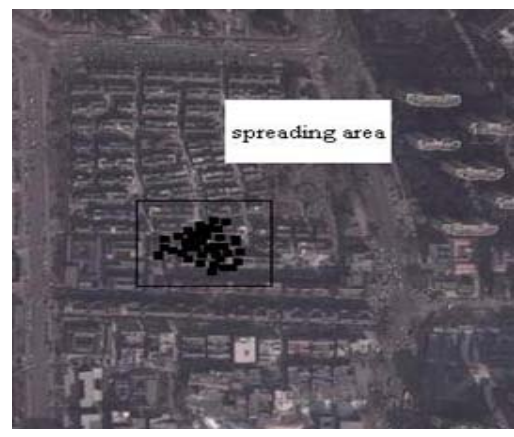

(b) $\mathrm{t}=1$ hour $30 \mathrm{~min}$

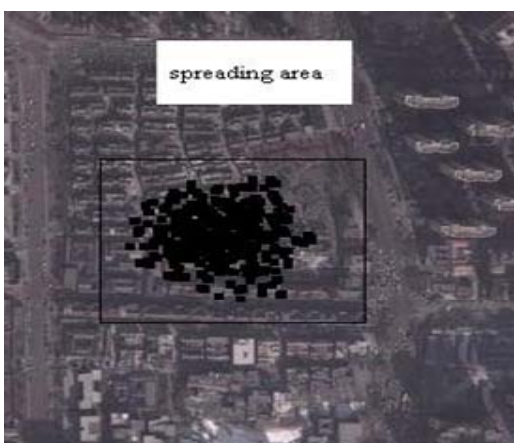

(c) $\mathrm{t}=2$ hour $30 \mathrm{~min}$

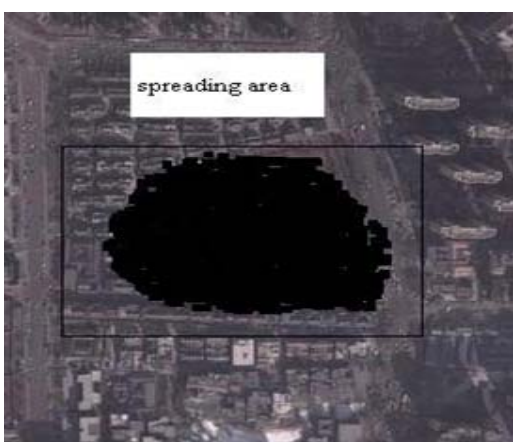

(d) $\mathrm{t}=3$ hour $30 \mathrm{~min}$

Fig. 2 Process of fire spreading in Drum-Tower District

\section{CONCLUSIONS}

This paper introduces a fire spread model for DrumTower District in Tianjin, based on a model of CA. According to recommended values in Drum-Tower District, the cell parameters are cell's characteristics, cell's states, and cell's size. The results of simulation in DrumTower District show that the model can provide a useful prediction for the fire spreading in Drum-Tower District. Future study be process in future by considering of more parameters such as humidity and the air condition to improve the accuracy.

\section{ACKNOWLEDGEMENTS}

This Project is supported by the undergraduate teaching quality and teaching reform project(NO:C030809), the national Spark Program(NO: 2013GA610013), the college Dr. fund(NO: 2012D05). 


\section{REFERENCES}

[1] Jiang YQ, Zhang P, Wong SC. and Liu RX, A higher-order macroscopic model for pedestrian flows, Physica A, 2010:46234635.

[2] Yang LZ, Fang WF, Huang R, Deng ZH,. Simulation of evacuation process based on cellular automaton model, Chin SciBull 2002: 896-901.

[3] Murosaki Y, Ohnishi K, Matsumoto K. Research on spreading factor of an urban expansion fire. Journal of the City Planning Institute of Japan, 1984: 373-378.

[4] Yue H, Shao CF, Yao ZS, Pedestrian evacuation flow simulation based on cellular automata, Acta Phys Sin, 2009:4523-4530.
[5] Varas A, Cornejo MD, Mainemer D, Toledo B, Rogan J, Mun , Cellular Automaton model for evacuation process with obstacles, Physica A, 2007: 631-642.

[6] Wakamatsu T. The risk of fire. In: Editorial Committee of Architectural Outline, ed. Architecture Outline No. 21: Theory of Architectural Fire Prevention. Tokyo, Syokokusya, 1978: 279-298.

[7] Jirou K, Kobayashi K. Large area fire. In: Fire Institute of Japan, ed. Fire Handbook (Third Edition). Tokyo: Kyoritsu Publication Co., Ltd., 1997.

[8] Kuang H, Song T, Li XL, Dai SQ, Subconscious Effect on Pedestrian 